\title{
Formadores em odontologia: profissionalização docente e desafios político-estruturais
}

\author{
The teaching of dentistry: professionalization \\ of university teaching and the challenges \\ of the political-structural dimension
}

Luciane Gabeira Secco 1

Maria Lúcia Toralles Pereira 2

1 Departamento de Saúde Pública, Faculdade de Medicina de Botucatu, Programa de Pós-graduação em Saúde Coletiva, Unesp. Campus de Rubião Júnior s/n, 18618-000, Botucatu SP. lucianesecco@uol.com.br

2 Departamento de Educação, Instituto de Biociências de Botucatu Programa de Pós-graduação em Saúde Coletiva, Unesp. toralles@laser.com.br
Abstract New social demands challenge the teaching practices of higher education in Dentistry. We investigated the concept of the quality of education, as seen by professors who work in the field of Dentistry. The universe of this study consists of the coordinators of the Undergraduate Course of those Schools of Dentistry in the State of São Paulo that offer programs for full graduate degrees (Master's and Doctorates). The tool employed for data collection was questionnaire and interview. The purpose of our work is to discuss signaling indicators capable of providing input for projects focusing on the professionalization of university teaching. The data collected were based on the political-structural dimension of the profession and the results pointed to a Dentistry facing a status crisis, challenges concerning the universalization of mouth healthcare to most of the population and its social impact. As a conclusion emerges the political and pedagogical project as a space for discussion the crisis, the changes in curricula, considering the social reality.

Key words Training of professor, Higher education, Health education, Dentistry, Quality of teaching in health sciences
Resumo $O$ texto trata das novas demandas à formação em odontologia e dos desafios da profissionalização da atividade docente. Investigam-se as concepções de qualidade do ensino de 13 coordenadores de cursos de graduação em odontologia do Estado de São Paulo, procurando indicadores que contribuam para a elaboração de propostas de formação docente, numa perspectiva crítica e reflexiva sobre qualidade e sobre problemas $d a$ realidade brasileira na área. A partir de depoimentos colhidos por questionário e entrevistas, busca-se compreender e analisar dados relativos à dimensão político-estrutural da profissão. Os resultados apontam para a crise da odontologia nos aspectos de número de escolas, exaustão do modelo de atendimento, dilema ético dos profissionais e diminuição de prestígio, com visível crise de status. Conclui-se que a transformação da crise em projeto político-pedagógico cria espaço para mudanças curriculares das faculdades de odontologia e acentua desafios quanto a orientações pedagógicas e competências da função docente.

Palavras-chave Formação docente, Ensino superior, Educação em saúde, Odontologia, Qualidade de ensino em saúde 


\section{Introdução}

Numa época de novas demandas sociais e amplos questionamentos em relação à qualidade das práticas pedagógicas que se desenvolvem no interior das Instituições de Ensino Superior (IES), a necessidade de rever a formação do professor universitário tem sido apontada por vários pesquisadores (Balzan, 1995; Cunha, 1999; Sobrinho, 1992). De um lado, a exigência de construir um projeto pedagógico pautado pelo princípio da qualidade, o que traz novas demandas ao coletivo dos cursos; de outro, a percepção de que a qualidade desse projeto depende muito de uma política de qualificação permanente do corpo docente como fundamento e garantia da qualidade do conjunto organizado de atividades acadêmico-científicas (Sobrinho, 1992).

A profissionalização docente passa a ser um desafio, visando possibilitar que as práticas nas IES se reorganizem, sobretudo, para dar conta de uma nova perspectiva epistemológica, onde as habilidades de intervenção no conhecimento sejam mais valorizadas do que a capacidade de armazená-lo (Cunha, 1999).

Neste cenário de novas demandas à prática docente, alguns estudos (Leite et al, 1998; Cunha, 1995) têm mostrado que as mudanças e inovações que desafiam a qualificação do corpo docente nos cursos de graduação não são percebidas da mesma forma nas diferentes áreas do conhecimento. Especificidades da área, relativas a uma epistemologia (lógica do conhecimento) nas faculdades de odontologia, e características da profissão odontológica, como os valores construídos e espaços de poder definidos no contexto da estrutura social e política, não podem ser desconsideradas quando se pensa em um projeto de formação docente para a educação superior.

A necessidade de pensar caminhos para a formação docente na área faz surgir algumas perguntas que balizaram a organização deste artigo: quais as concepções dos coordenadores de curso de graduação sobre as mudanças que desafiam a prática pedagógica em odontologia, tendo em vista as novas demandas sociais e a discussão sobre qualidade do ensino? Diante do desafio da profissionalização docente em uma perspectiva crítico-reflexiva, que características da profissão podem ser identificadas como marcos para ancorar mudanças pedagógicas no ensino de odontologia?

Para buscar respostas a essas perguntas, investigam-se as concepções de qualidade do en- sino daqueles que respondem, legalmente, pela elaboração dos currículos nas faculdades de odontologia: os coordenadores de graduação.

\section{Objetivos}

O objetivo principal deste artigo é analisar as concepções de qualidade de ensino universitário de professores que atuam como coordenadores de curso na área de odontologia, a partir de depoimentos colhidos por meio de questionário $\mathrm{e}$ entrevista, buscando dados que possam contribuir para a elaboração de propostas voltadas à formação docente em odontologia, considerando, de um lado, os desafios provocados pela presença dos processos avaliativos, da discussão sobre qualidade de ensino e das novas diretrizes curriculares brasileiras no meio acadêmico; e de outro, a necessidade ética de responder a essas demandas com uma postura crítica em relação à concepção de qualidade e aos problemas da realidade brasileira na área de odontologia.

\section{Abordagem teórico-metodológica}

Trata-se de pesquisa de caráter exploratório, descritivo e analítico, apoiada em abordagem qualitativa. A partir de questionário (com questões abertas e fechadas) e entrevista, investigam-se concepções sobre qualidade de ensino de coordenadores de graduação de cursos de odontologia do Estado de São Paulo.

O grupo de coordenadores que integra a pesquisa foi organizado com base em dois critérios: atuar em cursos de graduação em odontologia situados no Estado de São Paulo que apresentam cursos de pós-graduação strictosensu; e aceitar participar da pesquisa. O cenário do trabalho é o Estado de São Paulo onde, até o momento de encerramento da fase de levantamento de dados da pesquisa, por meio de questionário (janeiro de 2002), havia 14 cursos com programas de pós-graduação stricto-sen$s u$. As 14 escolas identificadas foram convidadas a participar da pesquisa, mas 13 coordenadores aceitaram.

Ressalta-se que o critério - ter pós-graduação stricto-sensu - foi utilizado porque essas instituições são formadoras da maior parte dos mestres e doutores do país e, por isso, consideradas parâmetros nacionais do ensino de odontologia, além de serem modelos de referência para possíveis inovações de ensino. 
A opção por trabalhar com os coordenadores se deve à dimensão de poder político que eles têm sobre os padrões de qualidade universitária e por estarem diretamente envolvidos com a elaboração de currículos, uma vez que as coordenações dos cursos de graduação, desde a Reforma Universitária de 1968, representam um colegiado, com responsabilidades definidas legalmente, sobre os assuntos ligados ao ensino. Os coordenadores têm legitimidade para discutir e formular currículos, dirigir e supervisionar o ensino, acompanhar a execução dos planos de ensino, avaliar a produtividade do processo de ensino-aprendizagem, buscar articulações com o Conselho de Ensino, Pesquisa e Extensão, por meio de representação docente. Pode-se dizer, portanto, que a qualidade do profissional formado pela universidade é da competência direta das coordenações de cursos (Sabadia, 2000). Embora, na prática, este poder nem sempre se encontre em suas mãos, os coordenadores são legalmente representantes da proposta de formação profissional em seus cursos e deveriam assumir papel decisivo num processo de mudança.

Além disso, ao focar os coordenadores de graduação das escolas que têm pós-graduação, buscam-se articulações entre a pós-graduação e a graduação, o que se constitui em uma tendência estimulada pelos órgãos oficiais (Coordenação de Aperfeiçoamento de Pessoal de Nível Superior /Capes). Essa articulação permite analisar a pós-graduação stricto-sensu como um espaço privilegiado para problematizar os desafios da formação docente, não só daqueles que estarão formando os futuros profissionais de odontologia nas Instituições de Ensino Superior mas, também, daqueles profissionais que já estão nos serviços, atuando em Programas de Saúde Coletiva, em práticas de prevenção e promoção da saúde bucal e na educação continuada de profissionais da área.

Cabe ressaltar que este artigo é parte de uma pesquisa mais ampla (Secco, 2003), que envolveu uma grande quantidade de dados para análise. Trata-se, portanto, de uma investigação em que se tem pouco controle sobre as variáveis que moldam a situação de interesse, definindo-se, assim, como trabalho mais de questionamentos do que de conclusões.

No primeiro momento de levantamento de dados foi aplicado o questionário a todos os coordenadores envolvidos com a pesquisa. $\mathrm{O}$ processo de análise exigiu uma forma de categorização a partir da agregação dos dados, reali- zada com base em três dimensões da formação profissional discutidas por Cunha (1995): questões político-estruturais (aspectos da estrutura de poder que interferem no ensino de odontologia e no cenário profissional do cirurgião-dentista, revelando ou problematizando valores anteriormente definidos); questões epistemológicas ou curriculares (relativas à especificidade da produção e apropriação do conhecimento na área de odontologia); e questões propriamente pedagógicas (aspectos relativos ao trabalho com o conhecimento na relação professor-aluno, incluindo procedimentos de ensino-aprendizagem, recursos etc., tendo em vista o projeto pedagógico do curso). Após essa primeira análise dos dados levantados pelo questionário, foram realizadas entrevistas com três coordenadores (de escolas públicas e particulares), em datas previamente agendadas, com a intenção de subsidiar a discussão do material. Essas entrevistas, gravadas e transcritas pelas pesquisadoras, tiveram a duração aproximada de 90 minutos.

Para a finalidade do artigo, privilegiaramse os dados qualitativos referentes às concepções dos coordenadores sobre as questões de qualidade relativas à dimensão político-estrutural da formação profissional, na classificação de Cunha (1995), buscando compreender, dentro dessa categoria, as características mais amplas da profissão .

Os dados agrupados nessa categoria foram interpretados com base em estudos de Minayo (1994), visando ao entendimento desses depoimentos no contexto da formação profissional em odontologia e associando, na análise, o olhar das pesquisadoras e a fala dos coordenadores, mediado pelas reflexões teóricas sobre educação, formação e qualidade no ensino superior dos autores que fundamentaram o estudo .

\section{A educação odontológica: alguns desafios}

Pode-se dizer que a prática odontológica no Brasil é resultado de um modelo institucionalizado pelas universidades e associações de classe, vinculados a componentes econômicos, políticos e ideológicos (Chaves, 1977). Embora o ensino de odontologia se caracterize como educação vocacional, "diretiva”, que tenta levar o estudante à aquisição de conhecimentos, habilidades e atitudes concentradas em torno de sua prática, os rumos que a educação odonto- 
lógica toma nem sempre podem ser compreendidos pelas exigências internas dessa prática.

A educação odontológica é um processo contínuo destinado a produzir profissionais capazes de manter ou restaurar o estado de saúde da cavidade bucal. O objetivo é produzir, eficientemente, um número suficiente de profissionais, com a qualidade adequada, capazes de produzir, entregar e distribuir serviços odontológicos da maneira mais econômica possível. As profissões existem para satisfazer uma necessidade social e a odontologia não é exceção. Ela opera em um sistema social, dentro do qual a profissão e suas instituições estão continuamente se reajustando de acordo com a mudança na tecnologia, os pontos de vista profissionais e as necessidades ou demandas da educação odontológica (Chaves, 1977).

Essas afirmações, no contexto de um sistema capitalista, no qual a produção não se destina diretamente ao consumo de bens necessários, mas objetiva o acesso, cada vez mais amplo, a bens e a diferentes formas de riqueza (Possas, 1999), mostram os desafios que a educação odontológica enfrenta em nosso sistema social. Assim, cabe lembrar que, por trás da estrutura educacional de um curso de odontologia, existe a indústria de equipamentos, de medicamentos e de materiais odontológicos influenciando, numa relação direta com as demandas do mercado, a prática profissional e, por conseqüência, a prática docente e o ensino em odontologia.

O mercado passou a influenciar a prática e a educação odontológica desde a metade do século 20, observa Narvai (1994). Ao analisar as propostas e ações relativas à prática odontológica no Brasil, no período entre 1952-1994, o autor afirma que o movimento do capital... fez aparecer e consolidou no Brasil uma odontologia de mercado, caracterizada pela produção-consumo privada de bens e serviços sob regulação do mercado (Narvai, 1994).

Trata-se de odontologia tecnicamente elogiável (pelo nível de qualidade e sofisticação inegavelmente alcançado nas diversas especialidades), cientificamente discutível (uma vez que não tem demonstrado competência para expandir esta qualidade para a maioria da população) e socialmente caótica (pela inexistência de impacto social ante as iniciativas e programas públicos e coletivos implementados) (Garrafa, 1993).

A análise dos processos de mudança no ensino de odontologia, ao longo do século 20, permite constatar que estes não ultrapassaram as preocupações técnicas de uma prática profissional altamente sofisticada e elitista. A necessidade da qualificação docente, já apontada por estudantes na década de 1950 (Vale e Pereira, 1957), não chegou a gerar desafios no contexto acadêmico da área, marcado pelo ideário do professor como profissional liberal bem-sucedido - condição, até recentemente, suficiente para legitimar a competência didático-pedagógica do professor de odontologia.

Somente no início dos anos 70, com a implementação dos cursos de pós-graduação e as exigências de titulação para a carreira universitária, obtidas em tais cursos e em concursos públicos, começa a se questionar a formação docente daqueles que comumente não receberam o mínimo de uma formação pedagógica e, como decorrência, apresentam dificuldades no exercício desta atividade que requer uma abordagem múltipla e complexa do processo ensinoaprendizagem (Perri de Carvalho, 2001).

Pressionados pelas Diretrizes Curriculares, desde o final de 2001, e pelo debate sobre qualidade e avaliação que se coloca em âmbito internacional, os cursos de odontologia começam a buscar caminhos que respondam a esses desafios: construção do Projeto Pedagógico do curso, mudanças curriculares e profissionalização do trabalho docente.

\section{Resultados e discussão}

Das 13 escolas que participaram da pesquisa, cinco são da rede privada e oito são públicas (uma municipal e sete estaduais). Considerando o critério de seleção das escolas, constata-se, no Estado de São Paulo, uma predominância de cursos de pós-graduação em instituições públicas, o que não significa que o número de programas de pós-graduação seja uniforme entre as escolas selecionadas.

Do total de escolas estudadas, nove localizam-se no interior do Estado (duas escolas privadas e sete públicas, sendo uma municipal e seis estaduais); e quatro na cidade de São Paulo (três escolas privadas e uma pública estadual). Mais da metade delas têm tempo de funcionamento superior a quarenta anos. Três dessas escolas datam do começo do século 20 incorporando, em seus cursos, todo o peso do modelo tradicional de ensino.

No conjunto das escolas analisadas, trabalham 1.254 professores, sendo 825 em escolas públicas e 429 em escolas privadas - dado que 
pode ser significativo no contexto de propostas de mudança educacional na área ou de construção de uma política de formação docente. Foi apontado, por coordenadores que, ao se comparar os processos de mudança vivenciados nas escolas públicas e particulares, esses processos tendem a se manifestar de modo mais rápido nas escolas particulares o que, para os mesmos, não quer dizer que esse processo ocorra da forma mais adequada. Na percepção de alguns coordenadores, há uma tendência de as escolas particulares enfrentarem as mudanças com maior rapidez para corresponderem às expectativas e orientações dos processos avaliativos, tendo em vista a maior instabilidade no emprego.

Na escola particular o processo de mudança é mais rápido, no sentido de que estas escolas tendem a se adequar às novas exigências. Nas escolas públicas, este processo está mais desarticulado, é mais lento, e, se as mudanças existem, na odontologia elas podem ser observadas de forma mais alinhada em Bauru, ... por condições especiais; Ribeirão Preto também... (relato de entrevista)

Chama a atenção, no levantamento dos dados, que somente $61,12 \%$ das vagas oferecidas para o $1^{\circ}$ ano dos cursos são preenchidas, indicando um momento de crise para as faculdades de odontologia, com o mercado de trabalho saturado, mesmo nas cidades de pequeno porte.

Do total de coordenadores de curso que participaram do estudo (13 sujeitos), 84,62\% atuam em regime de trabalho de tempo integral, sendo $61,53 \%$ em instituições públicas, confirmando a tendência do tempo integral para grande parte dos professores dessas instituições. Nas escolas particulares, apenas uma pequena parcela de professores trabalha em tempo integral.

Entre os coordenadores que participaram do estudo, $76,92 \%$ são do sexo masculino e, embora mais da metade deles atue na instituição há mais de doze anos, $61,54 \%$ exercem a função de coordenador há menos de cinco anos. Quase a totalidade $(92,31 \%)$ dos coordenadores atua como docente há mais de 12 anos, o que permite inferir que há uma familiaridade desse grupo de participantes com as questões do ensino nas suas escolas, condição relevante para que as respostas obtidas possam ser consideradas representativas no universo selecionado. Trata-se, assim, de um grupo de professores com algum tempo de experiência na docência e na instituição, sendo que $76,92 \%$ desses coor- denadores têm idades que variam entre 36 e 65 anos. Ao utilizarmos o estudo de Huberman (1992) para analisar as etapas da carreira docente, constatamos que $1 / 3$ dos coordenadores que participaram da pesquisa encontra-se em período próximo à aposentadoria. Considerando que o estudo referido, sobre professores em diferentes momentos da carreira docente, mostra que esses momentos tendem a caracterizarse por experiências e motivações também diferentes no que se refere ao enfrentamento das mudanças, sejam elas curriculares ou da prática pedagógica.

$\mathrm{Na}$ fala de um coordenador aparece a questão das diferentes fases, apontando para o papel que os jovens docentes tendem a ocupar nos cursos.

Os professores mais jovens, os professores associados, estão trazendo uma oxigenação maior ao curso .... Além disso, a pós-graduação está trazendo muita melhoria (relato de entrevista).

A titulação acadêmica foi apontada, com unanimidade, como um dos aspectos muito valorizados e visto, pela maioria dos coordenadores, como diferencial da qualidade docente. $\mathrm{Na}$ fala de um coordenador aparece, contudo, uma observação importante em relação a esse processo.

Hoje, os professores já estão sendo contratados como doutores nas escolas públicas. Isto é bom mas também tem um lado negativo: este professor perde, muitas vezes, a possibilidade de viver parte de sua formação, ao mesmo tempo, como aluno e como professor - condição que favorece a atuação do professor com os alunos, em sala de aula (relato de entrevista).

No contexto das escolas estudadas foi possível constatar que os processos de avaliação implantados e as Diretrizes Curriculares têm gerado um movimento de mudanças e muitos desafios à comunidade acadêmica da área de odontologia, tanto em termos curriculares (epistemológicos) como pedagógicos, apontando algumas contradições entre as concepções dos coordenadores.

Para conseguir melhorar o desempenho no Provão, várias escolas fizeram recuperação utilizando a disciplina de odontologia preventiva como nome fantasia. Eu não concordo... O Provão não pode ser parâmetro para medir qualidade; é somente uma proposta para ajudar a recuperar as faculdades em dificuldades (relato de entrevista).

Há escolas que estão transformando todas as clínicas em estágio supervisionado, o que tam- 
bém não concordo. Penso que as clínicas são destinadas ao desenvolvimento de habilidades... Discordo quando as diretrizes recomendam que o curso de odontologia tenha $20 \%$ em estágio supervisionado. Mas... o fato de as diretrizes serem "mandatárias"... (relato de entrevista).

Analisando a formação odontológica a partir das três dimensões identificadas por Cunha (1995), observa-se que, na dimensão políticoestrutural, a odontologia vivencia um momento de crise, seja pelo número de escolas no país, seja pela exaustão do modelo de atendimento, individual e elitista, predominante nos currículos das escolas brasileiras, ou, ainda, pela necessidade de se adaptar às exigências dos pacientes (determinadas e incentivadas pela grande mídia: jornais, revistas, programas de televisão). Em levantamento feito pelo Conselho Federal de Odontologia/CFO, a situação dos cursos de odontologia no Brasil mostra: 148 cursos de odontologia no Brasil, sendo 48 deles no Estado de São Paulo, com 23 novos registros de cursos aprovados, mas ainda não em funcionamento (Jornal do CFO, 2002).

A própria profissão vem sofrendo uma constante diminuição do seu prestígio com os alunos egressos do ensino médio. A odontologia sempre esteve entre as áreas mais concorridas nos vestibulares; hoje encontra-se em declínio. Vive uma crise relacionada ao status da profissão (cirurgião-dentista) no contexto social, que coloca em questão o prestígio e o poder dos profissionais em sua realidade social.

A odontologia está em crise; é necessário que ela se assuma como profissão das Ciências da Saúde. Houve um tempo em que o profissional era muito valorizado e muito bem remunerado. O profissional não se preocupava com o que estava fazendo porque chegava a trocar de carro todo o ano e não precisava refletir sobre a profissão. A profissão não é mais a mesma porque o profissional não tem força para negociar com os convênios, não tem como brigar (é briga de peixe grande!). São os convênios que estabelecem quanto vão pagar e como vão pagar ... e se o cirurgiãodentista não estiver interessado, hoje existem milhares de profissionais querendo essa oportunidade de trabalho (relato de entrevista).

Estes aspectos, associados ao ensino da prática voltada para o coletivo, com maior impacto social no contexto das políticas públicas de saúde, se manifestam como desafios a serem enfrentados no âmbito político-estrutural da formação odontológica. Ainda que pouco problematizados no contexto dos cursos, talvez porque, como apontou um coordenador em seu relato, o cirurgião-dentista é uma categoria profissional pouco politizada, cabe identificar nas características levantadas, aspectos que deverão ser considerados em qualquer proposta de profissionalização docente. Como comenta um coordenador: temos de ir pensando na formação dos alunos e na formação dos formadores, porque esses não dão a atenção devida a uma formação política dos profissionais.

\section{Considerações finais}

A odontologia há muito tempo ultrapassou os laços artesanais e artísticos e se consolida em bases científicas, buscando uma atuação social na área da saúde. A qualidade, em termos profissionais, depende de ações competentes, não somente para indicar e realizar habilidades e saberes que respondam a problemas específicos, mas para repensar o próprio papel do profissional diante dos problemas da realidade social, em um movimento de ação e reflexão. Nesse movimento dialético, em que novos valores são identificados na sociedade, a comunidade acadêmica busca caminhos que respondam às demandas da formação profissional em suas diferentes dimensões da prática.

Em pesquisa realizada na área (Secco, 2003), as crises e utopias em relação à qualidade do ensino de odontologia são mais explicitadas na dimensão pedagógica e mais encobertas na dimensão político-estrutural. Embora pouco explicitada, é a crise vivida nesta dimensão que parece problematizar efetivamente a qualidade da formação na área .

Ainda que a clínica possa suprir as necessidades individuais e privadas com qualidade técnica reconhecida, há um desafio em termos de abrangência: existe uma distância entre o ensino de odontologia e a perspectiva de universalização da saúde bucal em relação às demandas da realidade brasileira.

Romper essa distância exige políticas de formação do profissional que valorizem a presença do atendimento público e coletivo - fato que gera novos desafios à dimensão epistemológica do curso (prioridades de campos de saberes) e, também, à dimensão pedagógica (definição de estratégias de ensino-aprendizagem que poderão orientar um modo de ser e de agir enquanto profissional).

De outro lado, aparece a crise de prestígio da profissão - o status do cirurgião-dentista na 
organização social: a odontologia está em crise.... A profissão não é mais a mesma.... o profissional não tem força para negociar com os convênios..., como se constatou em relatos de entrevista. Apesar dessa crise abalar o prestígio e o poder do profissional no mundo do trabalho, como observa Botazzo (2000), a formação odontológica, na tentativa de negar a crise, procura perpetuar o status já alcançado enfatizando a competência técnica altamente especializada.

A crise vivida no espaço político-estrutural, explicitada por alguns coordenadores em relatos de entrevista, parece não ser tratada criticamente no contexto da formação odontológica: o aspecto político da formação do cirurgião-dentista não está sendo trabalhado (...) O cirurgiãodentista não tem força para elaborar programas e não temos representantes que sejam aceitos $e$ que tenham força, comentou um coordenador. A falta de uma formação mais politizada na área, que considere os desafios da realidade brasileira e problematize o imaginário profissional, se reproduz nos cursos de odontologia, dificultando a participação nas políticas de atendimento público, em termos de saúde bucal - sendo esse o espaço ocupado pela Saúde Coletiva nas faculdades de odontologia.

A problematização das demandas da sociedade, na perspectiva de superação das diferenças sociais, traz o desafio da eqüidade como um indicador ao conceito de qualidade nos cursos de odontologia e pode apontar caminhos na elaboração de um projeto social e educativo, comprometido com a cidadania, em uma visão crítico-transformadora, com a inclusão, em relação aos problemas de saúde bucal da população brasileira. Mas essa luta pela universalização da saúde bucal não pode deixar de considerar os valores subjetivos de autonomia e liberdade que cada grupo profissional tem no seu imaginário ou cada curso assume, como missão. Carrega implícita, no entanto, a idéia de que o conhecimento produzido precisa ser pensado não só como forma produtiva no contexto da realidade social, mas também, como instrumento de cidadania e transformação social, tendo em vista o compromisso de expansão do conhecimento para a maioria da população.

No Brasil, ainda se faz necessário que a educação aprimore seu trabalho, no sentido de superar o grave problema de exclusão social. $O$ desafio de valorizar o público e o coletivo exige novos caminhos em termos da formação profissional em odontologia. Talvez, tomando as palavras de Buarque (1994), o desafio da área, neste momento, seja o de formular novas perguntas. Em muitos casos, como diz o autor, a crise decorre da perda de capacidade para definir corretamente os problemas que precisam ser enfrentados pela formação, pela extensão e pelas pesquisas.

O desafio a ser enfrentado parece passar pela superação da dicotomia entre "formação geral versus formação específica”, mediante uma nova racionalidade capaz de incorporar a diversidade, as contradições e as tensões que constroem o cotidiano nas instituições de ensino superior.

Assim, no plano político-estrutural, podese dizer que um dos desafios ao ensino odontológico é discutir criticamente a crise, considerar a realidade brasileira e suas demandas, a especificidade do conhecimento técnico-científico na área de odontologia e o projeto político-social que a profissão pode e quer assumir.

A transformação dessa crise em utopia, em tarefa realizável, consciente da provisoriedade de cada proposta numa sociedade em transformações aceleradas, exige esforços combinados entre as instituições de ensino (os cursos de odontologia que, timidamente, começam a estabelecer uma ponte entre eles) e a sociedade, percebendo que a relação entre esta e aquelas não é simples: exige a percepção de que, do lado da sociedade, as demandas são múltiplas e, freqüentemente, imediatistas e contraditórias, como observa Sobrinho (1995); do lado das instituições de ensino é preciso perceber que os processos de abertura e interação com o mundo social e econômico precisam de um projeto político-pedagógico consistente apoiado em fundamentos teórico-metodológicos discutidos no coletivo dos cursos.

Esta mudança de foco na formação do profissional de odontologia cria espaço para mudanças no imaginário da profissão - mudanças que podem recuperar o prestígio profissional em outra dimensão social do trabalho: não só na perspectiva da qualidade técnica especializada, cujo nível de qualidade e sofisticação foi inegavelmente alcançado nas diversas especialidades, mas, também, na perspectiva científica e social, investindo em expandir essa qualidade alcançada para a maioria da população, com maior impacto social em programas públicos e coletivos (a própria inserção da saúde bucal no Programa de Saúde da Família pode ser um exemplo dessa possibilidade). Cria, também, novos desafios em termos de estrutura curricu- 
lar, orientações pedagógicas e competências da função docente, cujo enfrentamento não pode desconsiderar a especificidade do conhecimento na área e as características da profissão no mundo do trabalho.

Competência é saber fazer bem, visto através das dimensões técnicas e políticas mediadas pela ética (Rios, 2001).

\section{Referências bibliográficas}

Balzan N 1995. A voz do estudante: sua contribuição para a deflagração de um processo de avaliação institucional, pp.115-47. In JD Sobrinho \& NC Balzan (orgs). Avaliação institucional: teoria e experiências. Ed. Cortez, São Paulo.

Botazzo C 2000. Da arte dentária. Hucitec, São Paulo.

Buarque C 1994. A aventura da universidade. Ed. UnespPaz e Terra, São Paulo-Rio de Janeiro.

Chaves MM 1977. Odontologia social. Editorial Labor, Rio de Janeiro.

Cunha MI 1999. A avaliação da aprendizagem no ensino superior. Avaliação / Rede de Avaliação Institucional da Educação Superior. RAIS 4(14):7-13.

Cunha MI 1995. Implicações da estrutura político estrutural das carreiras profissionais nos currículos da universidade. Puccamp (2):3-21.

Garrafa V 1993. Saúde bucal e cidadania. Saúde em Debate (41):50-57.

Huberman M 1992. O ciclo de vida profissional dos professores, pp. 31-62. In A Nóvoa (org.). Vida de professores. Porto Ed., Porto.

Leite D, Braga AM, Fernandes C, Genro ME \& Ferla A 1998. Avaliação institucional e os desafios da formação do docente na universidade pós-moderna, pp. 3956. In MT Masetto (org.). Docência na universidade. Papirus, Campinas.

Minayo MCS (org.) 1994. Pesquisa social: teoria, método e criatividade. Ed. Vozes, Petrópolis.

Narvai PC 1994. Odontologia e saúde bucal coletiva. Hucitec, São Paulo.
Perri de Carvalho AC 2001. Ensino de odontologia em tempos de LDB. Ed. Ulbra, Canoas.

Possas CA 1999. Prioridades sanitárias, ciência e tecnologia, pp. 243-257. I Conferência Nacional de Ciência e Tecnologia em Saúde. Ministério da Saúde, Brasília.

Rios TA 2001. Compreender e ensinar: por uma docência de melhor qualidade. Ed. Cortez, São Paulo.

Sabadia JAB 2000. O papel da coordenação de curso: a experiência no ensino de graduação em geologia na Universidade Federal do Ceará. Educação em Debate. 21(39):58-62.

Secco LG 2003. O ensino de odontologia no Estado de São Paulo: as concepções de qualidade dos coordenadores de cursos de odontologia, Botucatu. Dissertação de mestrado. Faculdade de Medicina, Universidade Estadual Paulista, Botucatu.

Sobrinho JD 1995. Universidade: processos de socialização e processos pedagógicos, pp.15-36. In JD Sobrinho \& NC Balzan (orgs.). Avaliação institucional: teoria e experiências. Ed. Cortez, São Paulo.

Sobrinho JD 1992. Universidade: projeto, qualidade, avaliação e autonomia. Pro-Posições 3(7):7-17.

Vale M \& Pereira, DBI 1957. Seminário de reforma do Ensino odontológico: sugestões apresentadas. Revista de Farmácia e Odontologia 23 (197):249-50.

Artigo apresentado em 16/9/2003

Aprovado em 29/10/2003

Versão final apresentada em 17/11/2003 